\title{
Thermal, Rheological and Morphological Properties of Poly (Lactic Acid) (PLA) and Talc Composites
}

\author{
Talita Ferreira Cipriano, Ana Lúcia Nazareth da Silva \\ Instituto de Macromoléculas Professora Eloisa Mano - IMA, \\ Universidade Federal do Rio de Janeiro - UFRJ
}

\author{
Antonio Henrique Monteiro da Fonseca Thomé da Silva \\ Departamento de Engenharia Agrícola e Meio Ambiente, Universidade Federal Fluminense - UFF \\ Ana Maria Furtado de Sousa, Gustavo Monteiro da Silva \\ Instituto de Química da Universidade - IQ, Universidade do Estado do Rio de Janeiro - UERJ \\ Marisa Guimarães Rocha \\ Instituto Politécnico Campus Regional - IPRJ, Universidade do Estado do Rio de Janeiro - UERJ
}

\begin{abstract}
In this study, composites based on poly(lactic acid) (PLA)/talc were prepared at different compositions by melt mixing in a twin screw extruder. The effect of a nucleating agent, talc, on the crystallization behavior, rheological and morphological properties of PLA was investigated. DSC results showed that the addition of the mineral filler in the range between 1 and 5 wt. \% to the PLA matrix increases the degree of crystallinity. This finding shows that talc acted as a nucleating agent for PLA during the processing stage. The composites morphology was also studied using a scanning electron microscope (SEM). The micrographs showed that a good dispersion of talc was achieved in all compositions analyzed. The rheology of PLA/talc composites was evaluated with the dynamic mode and correlated with the aforementioned observed morphology. The results showed that the addition of the mineral filler to the PLA matrix decreased system viscosity, thus highlighting the filler's lubricant effect. As talc content increased, system's viscosity also increased, providing material with higher elastic behavior. Thermal analysis showed that the composition of $3 \mathrm{wt} . \%$ of talc added to polymer matrix seems to be interesting with regard to the need of articles possessing good dimension stability.
\end{abstract}

Keywords: PLA, nucleating agent, talc, composites, properties.

\section{Introduction}

Biobased and biodegradable polymers are regarded as a sustainable alternative to current petroleum based materials and have already found acceptance in areas such as food packaging, bags and sacks, loose fill packaging agricultural film among other market applications ${ }^{[1,2]}$. Poly (lactic acid) (PLA) is a well-known biodegradable aliphatic polyester resin (Figure 1) and it is widely used not only for so-called simple applications, such as cups, but also for packaging and biomedical applications ${ }^{[3-5]}$. Nowadays, more advantageous applications of the environmentally friendly resins are under development for cars as well for computer parts, which bring forward the demand for improvement in crystallization, and in thermal and mechanical properties of the PLA-based products $^{[6]}$.

According to Pantani et al. ${ }^{[7]}$, the range of PLA applications is severely limited by its low glass transition temperature $(\mathrm{Tg})$, which is around $60{ }^{\circ} \mathrm{C}$. The authors also reveal that PLA crystallinity can lead to significant improvements in stiffness, strength, heat deflection temperature as well as in chemical resistance; however, producing a highly crystalline article of PLA is still challenging due to the low crystallization rate. In processes such as injection molding, where the orientation is limited and the cooling rate is high, it is even more challenging to obtain significant crystallinity values and, thus, formulation or process changes are required ${ }^{[8]}$. Nucleating agents (NAs) are widely used for semicrystalline polymers in order to accelerate crystallization rate. It acts lowering the surface free energy barrier related to nucleation and, thus, initiates crystallization at higher temperature upon cooling ${ }^{[8,9]}$. Several chemicals suitability as NAs for PLA has been evaluated and talc has been widely used in such applications ${ }^{[9]}$. Li and Huneault ${ }^{[8]}$ revealed that the crystallization half-time can be reduced by more than one order of magnitude to less than 1 min when $1 \%$ talc is added. However, it's important to be aware of the potential reduction in overall mechanical properties of PLA as mineral filler is added to polymer matrix. In this paper, poly(lactic acid) and talc composites were evaluated under different compositions. The aim of this work is to investigate the effect of the mineral filler - talc, obtained from a Brazilian industry, on the rheological, thermal and morphological properties of PLA matrix and to contribute to the development of composites from biodegradable polyesters.

Corresponding author: Ana Lúcia Nazareth da Silva, Instituto de Macromoléculas Professora Eloisa Mano - IMA, Universidade Federal do Rio de Janeiro - UFRJ, Av. Horácio Macedo, 2030, Bloco J, Cidade Universitária, Ilha do Fundão, CEP 21941-598, Rio de Janeiro, RJ, Brasil, e-mail: ananazareth@ima.ufrj.br 
<smiles>CC(C)C(=O)C(C)OC(C)C(=O)OC(C)C(=O)O</smiles>

Figure 1. PLA structure.

\section{Experimental}

\section{Materials}

Poly (lactic acid) (PLA) (INGEO 2003D) was supplied by Natureworks LLC. The commercial mineral filler, talc, was donated by Magnesita Company. Table 1 shows the characterization of the PLA used in this work and Table 2 shows the physical characteristics of talc, the mineral filler used as nucleating agent.

Figure 2 Shows the micrographs of the talc particles obtained by using a Jeol scanning electron microscope (SEM), model JSM 5610 LV, from IMA laboratory.

\section{PLA/talc composite preparation}

PLA and PLA/talc composites, containing different content of talc: $0 \%$ (sample A), $1 \%$ (sample B), $3 \%$ (sample C), 5\% (sample D) and 7\% wt\% (sample E), were mixed in a plastic bag in order to improve their dispersion. Subsequently, the pure PLA and the composites were processed in a twin-screw co-rotating extruder (TeckTril, model DCT-20) with $20 \mathrm{~mm}$ diameter and a length to diameter (L/D ratio) equal to 36 at $200 \mathrm{rpm}$. A temperature profile set at $140 / 210 / 210 / 220 / 220 / 210 / 200 / 200 / 200 / 190 \quad{ }^{\circ} \mathrm{C}$ was adopted. Figure 3 shows the screw profile used in the experiments.

The obtained extrudates were later pelletized in a granulator and subsequently kept for drying in the oven at $60{ }^{\circ} \mathrm{C}$. Injected samples for mechanical analysis were prepared in a Arburg Injector, model 270S following the processing parameters and temperature profile presented in Tables 3 and 4, respectively.

\section{Characterization of PLA and PLA/talc composites}

\section{Rheological analysis}

The oscillatory flow properties namely the complex viscosity * (defined as * ${ }^{*} \eta^{\prime}-$ i $\eta$ ', where $\eta^{\prime}$ is the dynamic viscosity or the real part of the viscosity and in" is the imaginary part of the viscosity); the storage modulus, G' (defined as $G^{\prime}=\omega \eta$ ", where $\omega$ is the frequency of the oscillation in $\mathrm{rad} / \mathrm{s}$ ) and the loss modulus, G" (defined as G" = $\omega \eta$ ') of the pure PLA and its composites were determined in a TA Instruments rheometer, model AR 2000. A strain sweep test was initially conducted to determine the linear viscoelastic region of the materials. Dynamic frequency sweep test (strain: $5 \%$; frequency: 0.01 to $600 \mathrm{rad} / \mathrm{s}$ and temperature at $190{ }^{\circ} \mathrm{C}$ ) were subsequently performed to determine the dynamic properties of the materials, using a parallel-plate geometry with $25 \mathrm{~mm}$ of diameter.
Table 1. PLA Characterization.

\begin{tabular}{lcc}
\hline \multicolumn{1}{c}{$\begin{array}{c}\text { Physical and Mechanical } \\
\text { Properties }\end{array}$} & $\begin{array}{c}\text { INGEO } \\
\text { 2003D }\end{array}$ & $\begin{array}{c}\text { ASTM } \\
\text { Method }\end{array}$ \\
\hline Specific gravity & 1.24 & D792 \\
MFI, g/10 min $\left(210^{\circ} \mathrm{C}, 2.16 \mathrm{~kg}\right)$ & 6 & $\mathrm{D} 1238$ \\
Tensile strength at break, MPa & 53 & D882 \\
Tensile yield strength, MPa & 60 & D882 \\
Tensile modulus, GPa & 3.5 & D882 \\
Notched Izod Impact, J/m & 16 & D256 \\
$\mathrm{Mn}^{*}, \mathrm{~g} / \mathrm{mol}$ & 114317 & - \\
$\mathrm{Mw}^{*}, \mathrm{~g} / \mathrm{mol}$ & 181744 & - \\
$\mathrm{DMM}^{*}$ & 1.59 & - \\
\hline
\end{tabular}

*GPC measurements in a Viscotek equipment.

Table 2. Physical characteristics of talc.

\begin{tabular}{lc}
\hline BET Surface Area, $\mathrm{m}^{2} / \mathrm{g}^{\mathrm{a}}$ & 5.97 \\
Volume of pores, $\mathrm{cm}^{3} / \mathrm{g}^{\mathrm{a}}$ & 0.0203 \\
Average pore diameter, $\AA^{\mathrm{a}}$ & 45.55 \\
Particle diameter, $\mathrm{D}-50(\mu \mathrm{m})^{\mathrm{b}}$ & 11.58 \\
\hline
\end{tabular}

a) Measured in IMA laboratory using ASAP 2010 V3.01 equipment. b) Measured in CETEM laboratory using MALLS, Hydro 2000 SM equipment.

\section{Thermal analysis}

A TA Instruments DSC apparatus, model Q 1000, was used to determine the melting and recrystallization behavior of the PLA and its composites. Differential Scanning Calorimetry (DSC) tests were run under the following cycles: heating from $40{ }^{\circ} \mathrm{C}$ to $220{ }^{\circ} \mathrm{C}$ at a heating rate of $5{ }^{\circ} \mathrm{C} \cdot \mathrm{min}^{-1}$ and cooling down to $40{ }^{\circ} \mathrm{C}$ at a cooling rate of $5^{\circ} \mathrm{C} \cdot \mathrm{min}^{-1}$. Nitrogen atmosphere was employed during the experiment, using $50 \mathrm{ml} / \mathrm{min}$ of flow rate.

\section{Morphological analysis}

The morphology of the PLA and its composites was examined in a Jeol Scanning Electron Microscope (SEM), model JSM 5610 LV from fracture surfaces after tensile test. The dispersion of the filler on the PLA matrix was observed at an accelerating voltage of $25 \mathrm{kV}$.

\section{Results and Discussion}

\section{Rheological measurements}

Figure 4 shows the dependence of the logarithm of the value of the complex viscosity $\left(\eta^{*}\right)$ on the logarithm of investigated frequencies for PLA and PLA/talc composites. As shown, up to around $10 \mathrm{rad} . \mathrm{s}^{-1}$, PLA and its composites showed a Newtonian behavior. After such value, they exhibit a general decrease in viscosity value with increasing frequency, i. e., PLA and PLA/talc composites show pseudoplastic behavior. By definition polymer melts are considered pseudoplastic because their viscosity decreases with the increasing of shear stress. Therefore, they are psedoplastic fluids.

It was also observed that PLA presents a higher viscosity in the whole range of the explored frequency and, as talc is added to the polymer matrix (regardless the amount of it), a decrease in viscosity values was observed 


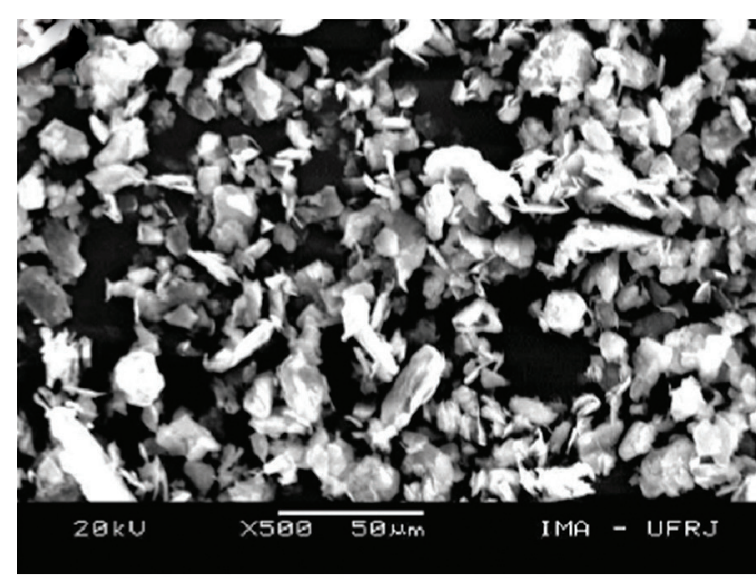

(a)

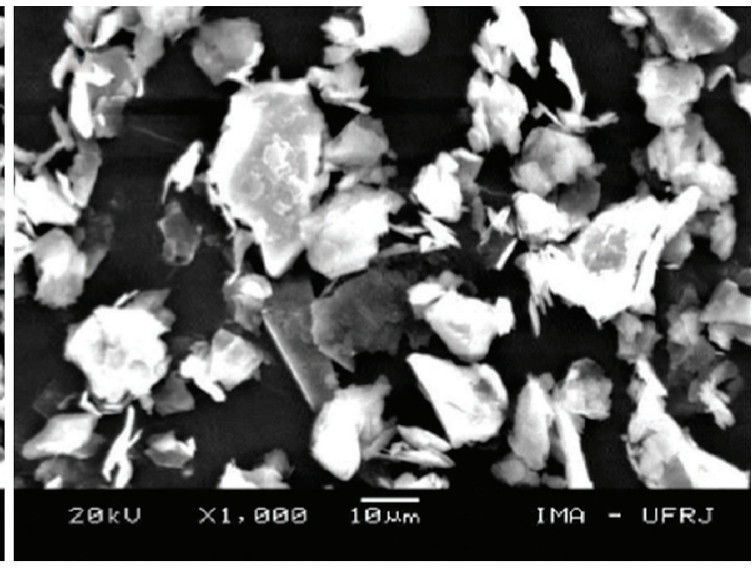

(b)

Figure 2. SEM micrographs of talc particles (a) $500 \mathrm{x}$; (b) $1000 \mathrm{x}$.

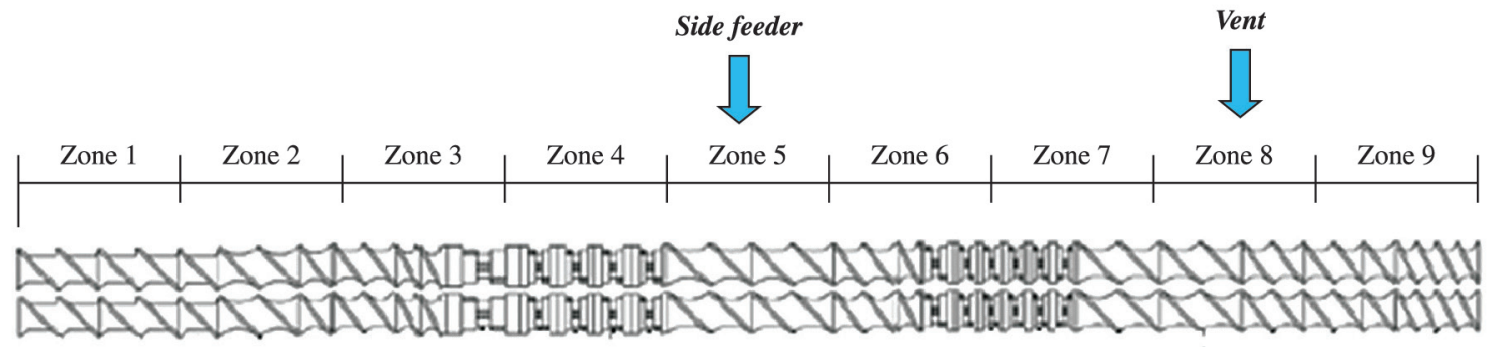

Figure 3. Screw profile - TeckTril twin screw (IMA/UFRJ).

Table 3. Processing parameters for injection molding used for material preparation.

\begin{tabular}{ccccc}
\hline Injection Pressure (bar) & Injection Speed $\left(\mathbf{c m}^{3} / \mathbf{s}\right)$ & Mold Temperature $\left({ }^{\circ} \mathbf{C}\right)$ & Back Pressure (bar) & Back Time (s) \\
\hline 800 & 60 & 30 & 500 & 4 \\
\hline
\end{tabular}

Table 4. Injection molding temperature profile used for material preparation.

\begin{tabular}{cccccc}
\hline Zone & $\mathbf{Z}=\mathbf{1}$ & $\mathbf{Z}=\mathbf{2}$ & $\mathbf{Z}=\mathbf{3}$ & $\mathbf{Z}=\mathbf{4}$ & $\mathbf{Z}=\mathbf{5}$ \\
\hline Temperature $\left({ }^{\circ} \mathrm{C}\right)$ & 180 & 190 & 200 & 210 & 220 \\
\hline$Z$
\end{tabular}

$\mathrm{Z}=1$ : Feed zone; $\mathrm{Z}=2-3$ : Compression zone; $\mathrm{Z}=4$ : Metering zone; $\mathrm{Z}=5$ : Die zone.

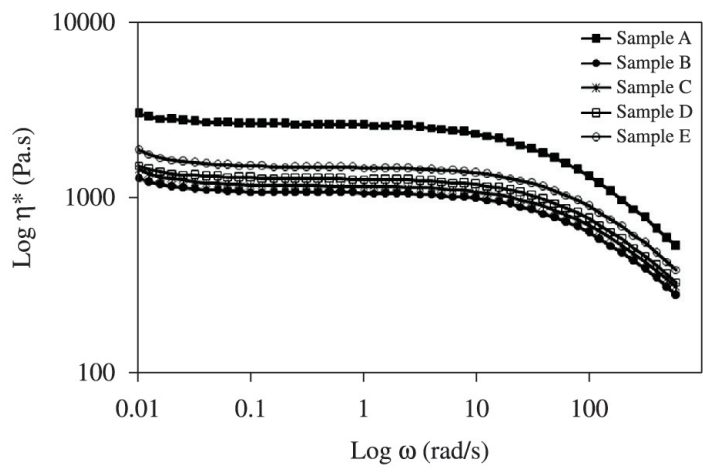

Figure 4. $\log \left(\eta^{*}\right)$ versus $\log (\omega)$ for PLA and PLA/talc composites. $0 \%$ (sample A $-100 \%$ PLA reference), $1 \%$ (sample B), 3\% (sample C), 5\% (sample D) and 7\% (sample E).

compared to pure PLA. This behavior can be related to the lubricant effect of the mineral filler on the PLA chains. This effect should be related to the lamellae exfoliation of the additive particles, since the interaction between them are maintained just by Van der Waals forces. Due to it, the slippage between the particles and the macromolecules is facilitated, leading to a decrease in the polymer chain strength against shear imposed during the analysis. Similar results were observed in the literature ${ }^{[10]}$.

However, as the talc content increased, an increasing in the viscosity values was observed. This behavior might be associated with restriction of chain mobility caused by the reinforcing effect of the filler on the PLA matrix. Similar results were also presented in the literature ${ }^{[11]}$.

The effect of the mineral filler as a lubricant for PLA chains is further explored in Figure 5, where the zero-shear viscosity is presented as a function of talc content. When 1 wt. $\%$ of talc was added, a significant decay of the viscosity is observed. This behavior is a typical plasticizer effect. However, when a higher filler content is added, an apparent increasing of the viscosity values occurred, indicating that talc hampers the flow of the polymer chains. For all contents evaluated, the composites' viscosity values are still lower than the PLA $\eta_{0}$ values. 


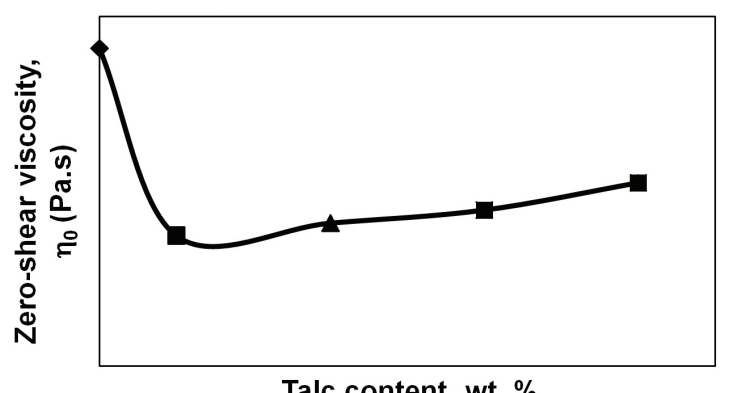

Talc content, wt. \%

Figure 5. Zero-shear viscosity versus talc content.

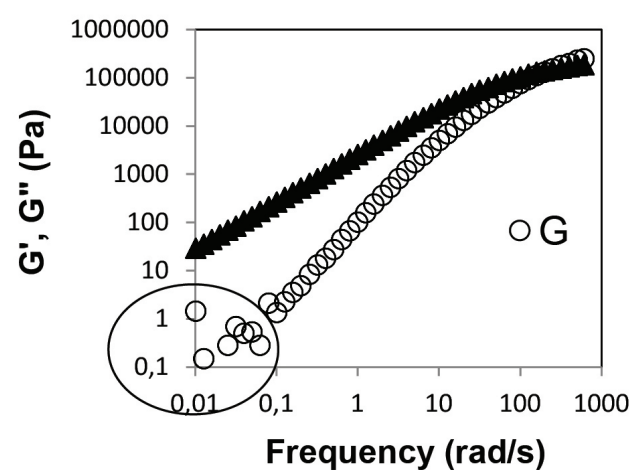

(a)

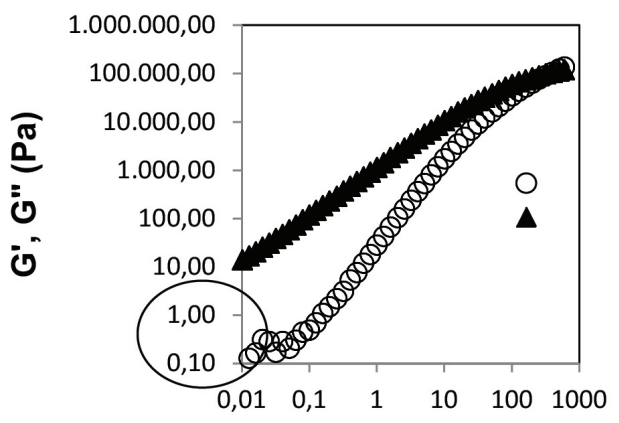

Frequency (rad/s)

(c)
As reported in the literature ${ }^{[12-14]}$, all viscoelastic materials behave more or less as solid-like (elastic) and liquid-like (viscous) depending on the rate at which they are being deformed. This behavior is related to the fact that strained macromolecules tend to pull back to the original shape. The dynamic storage modulus, G', is related to the elastic behavior of the material and may be considered as the amount of the stored energy. The dynamic loss modulus, G", represents the amount of dissipated energy. The dependence of G' and G' on the frequency measures the relative motion of all molecules in the bulk and can give important information about the flow behavior of melts. In Figure 6 the dependence of

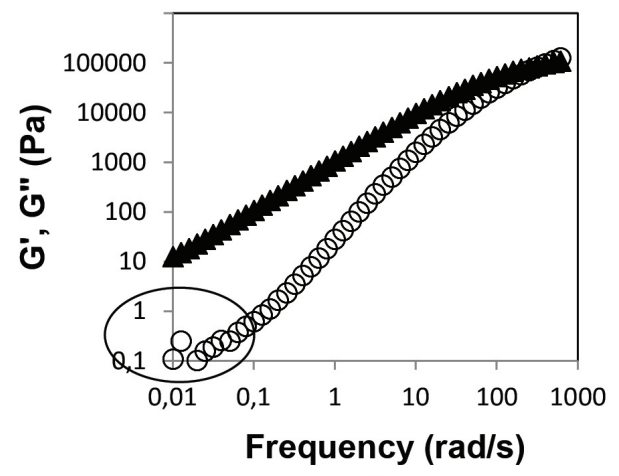

(b)

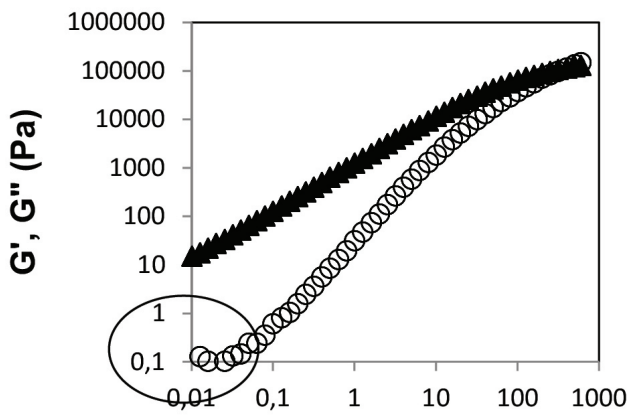

Frequency ( $\mathrm{rad} / \mathrm{s})$

(d)

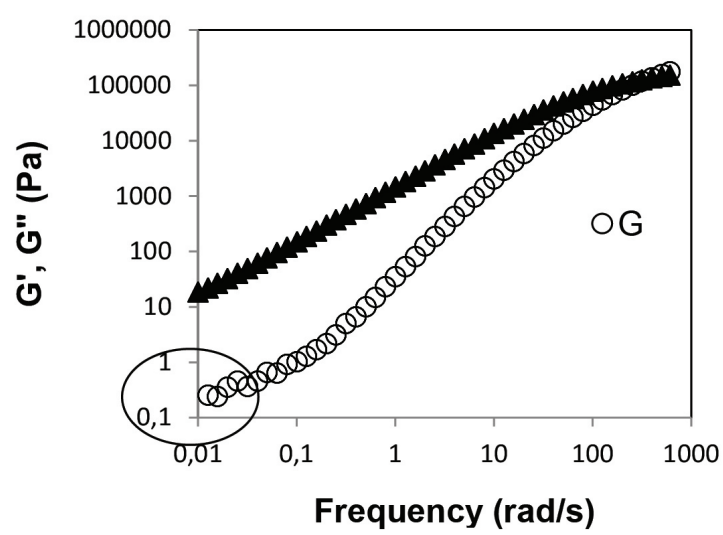

(e)

Figure 6. Dynamic properties versus frequency (a) Sample A; (b) Sample B; (c) Sample C; (d) Sample D and (e) Sample E 0\% (sample A - 100\% PLA reference), $1 \%$ (sample B), 3\% (sample C), 5\% (sample D) and 7\% (sample E). 
the elastic modulus, G', loss modulus, G', and complex viscosity, $\eta^{*}$, on the investigated frequencies of PLA/talc composites are compared with those of the pure PLA.

The figure shows that PLA presents a flow instability at lower frequency regions, observed in the G' curves. This instability becomes less evident as talc content was increased, indicating that the elastic behavior of PLA becomes more stable at low frequency by the addition of talc in the polymeric matrix. In other words, these results indicate that PLA composites with more elastic behavior tend to be produced.

Table 5 shows the crossover point values of the samples and the frequencies where they occurred. In the materials studied, the G" values were higher in almost all the frequency range analyzed in relation to the G' curves.

The results show that as talc was added (1 wt., \%) to PLA matrix, a decreasing in the cross point and an increasing in frequency values was observed. It indicates that materials with more viscous behavior (lower viscosity) were produced.

Table 5 also shows that as the concentration of talc in the composites increases, there is an increase of the $\mathrm{G}^{\prime} / \mathrm{G}^{\prime}$ ' at the crossover point and $\mathrm{w}_{\mathrm{c}}$ remains constant. However, the G'/G" value obtained at higher content of talc is lower than that presented by the pure polymer. The $\mathrm{w}_{\mathrm{c}}$ value of PLA is lower than those presented by PLA/Talc composites. It indicates that materials tend to be produced with more elastic behavior as talc content increased.

Table 5. Modulus and frequency values in the cross point G'/G' for the analyzed compositions.

\begin{tabular}{ccc}
\hline Sample Codes & $\begin{array}{c}\text { Modulus at } \\
\text { Crossover point, } \\
\text { G'=G'(Pa) }\end{array}$ & $\begin{array}{c}\text { Crossover point }\left(\omega_{\mathbf{c}}\right) \\
(\mathbf{r a d} / \mathbf{s})\end{array}$ \\
\hline A & 157400 & 251 \\
B & 99130 & 398 \\
C & 107700 & 398 \\
D & 117100 & 398 \\
E & 137300 & 398 \\
\hline
\end{tabular}

Table 6. Shear thinning exponent, n, for PLA and PLA/talc composites.

\begin{tabular}{cc}
\hline Sample Codes & $\mathbf{n}$ \\
\hline A & -0.01 \\
B & -0.01 \\
C & 0.00 \\
D & 0.00 \\
E & 0.00 \\
\hline
\end{tabular}

As mentioned, dynamic rheological testing reveals information about polymer chain structure and dynamics. In Figures 4 and 6, it can be observed that PLA and PLA/ talc composites show a Newtonian behavior up to around $10 \mathrm{rad} . \mathrm{s}^{-1}$ and then, a slight decrease in viscosity values was observed, as seen before. Similar behavior was observed by Li and Huneault ${ }^{[8]}$ in their studies.

Wagener and Reisinger ${ }^{[15]}$ evaluated the rheological behavior of systems based on poly(butylenes terephthalate) (PBT) as matrix polymer and added clay. A similar study was performed by Souza et al. ${ }^{[16]}$ with PLA/ synthetic mica nanocomposites. The authors used the power law expression to evaluate the rheological behavior

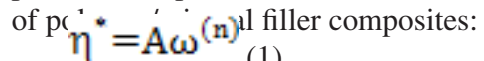

with $\eta^{*}$ as complex apparent viscosity; $A$, a sample specific pre-exponential factor; $\omega$, the oscillation frequency used and $n$, the shear thinning exponent.

Table 6 presents the values of $n$ determined from PLA and PLA/talc curves presented previously. The data confirm that the pure polymer and the composites show a perfect Newtonian behavior at the range of frequency studied, resulting in a shear thinning exponent close to zero.

\section{Thermal properties}

The thermal properties of samples consisting of pure PLA and PLA/talc composites, with lower talc content (up to 5 wt.\%) are listed in Table 7. It was decided to evaluate the thermal properties just for composites with lower talc content. It was observed in the rheological results that above $5 \mathrm{wt} . \%$, the mineral filler tended to acted as a reinforcing agent. All of the thermal properties were obtained from the first heating curves in order to evaluate the effect of the mineral filler, as nucleating agent, during the processing. The temperature $T_{c c}$, also presented in the table, is the cold crystallization temperature. Figure 7 shows the DSC melting and cooling thermograms.

It's known that the physical, mechanical and barrier properties of PLA are dependent on its the solid-state morphology and crystallinity. Accordingly, PLA thermal properties are strongly dependent on its thermal history ${ }^{[17]}$.

It can be seen in Table 7 and Figure 7 that the $\mathrm{Tg}$ of PLA was not greatly affected by the addition of the nucleating agent, in on the range of compositions analyzed. As expected, the neat PLA exhibited no crystallization peak upon cooling due to the very slow crystallization rate characteristics of PLA. On the other hand, the crystallization temperature on heating $-T_{c c}$, was affected by the addition of 3 wt.\% of the mineral filler. According to Kang et al. ${ }^{[1]}$, a lower crystallization temperature on heating indicates faster crystallization.

Table 7. The effect of nucleating agent, talc, on the thermal properties of PLA.

\begin{tabular}{cccccccc}
\hline Sample Codes & $\mathbf{T}_{\mathrm{g}}\left({ }^{\circ} \mathbf{C}\right)$ & $\mathbf{T}_{\mathrm{c}}{ }^{*}\left({ }^{\circ} \mathbf{C}\right)$ & $\Delta \mathbf{H}_{\mathrm{c}}{ }^{*}(\mathbf{J} / \mathbf{g})$ & $\mathbf{T}_{\mathrm{m}}\left({ }^{\circ} \mathbf{C}\right)$ & $\Delta \mathbf{H}_{\mathrm{m}}(\mathbf{J} / \mathbf{g})$ & $\mathbf{T}_{\mathrm{cc}}\left({ }^{\circ} \mathbf{C}\right)$ & Crystallinity $(\boldsymbol{\%})$ \\
\hline A & 55 & 105 & 28.88 & 153 & 29.62 & - & - \\
B & 56 & 100 & 24.72 & 154 & 28.76 & - & 4.34 \\
C & 55 & 101 & 22.81 & 154 & 29.18 & 91 & 6.85 \\
D & 53 & 100 & 29.70 & 155 & 37.72 & - & 8.62 \\
\hline
\end{tabular}

$* \mathrm{~T}_{\mathrm{c}}$ and $\Delta \mathrm{H}_{\mathrm{c}}$ are the crystallization temperature and heat of crystallization, respectively, on the first heating curve. 


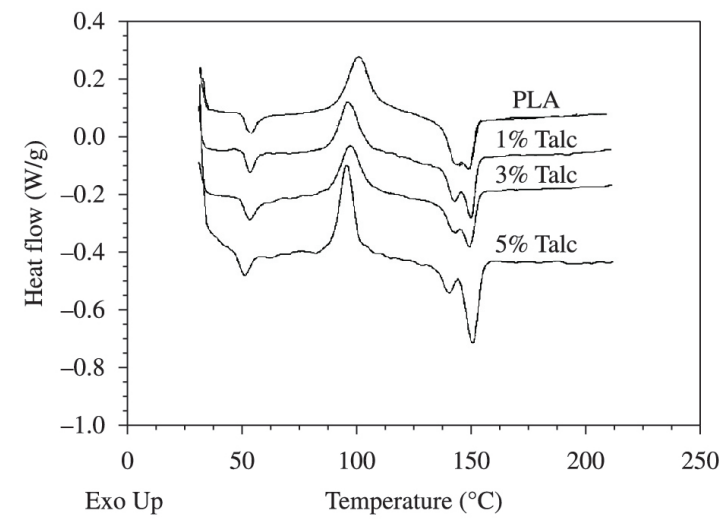

(a)

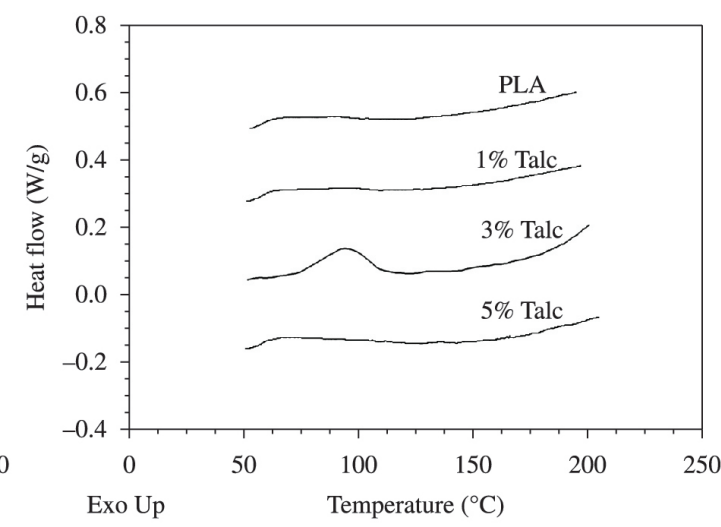

(b)

Figure 7. DSC scans of pure PLA and PLA/talc composites (a) melting thermograms and (b) cooling thermograms.

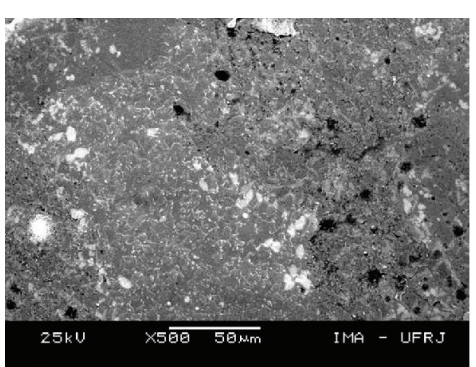

Sample A

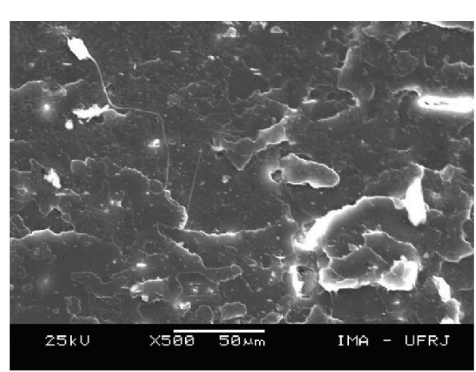

Sample B

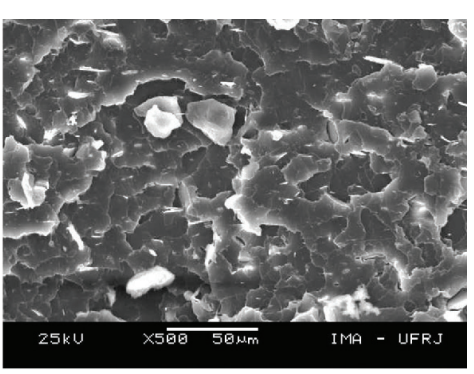

Sample C

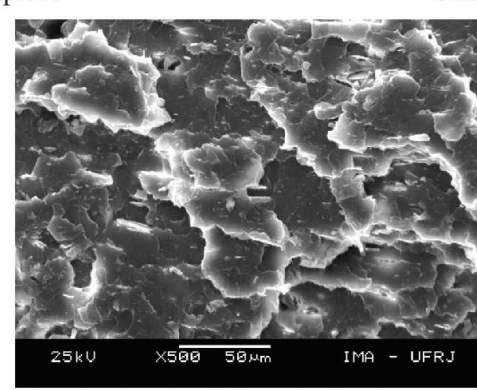

Sample D

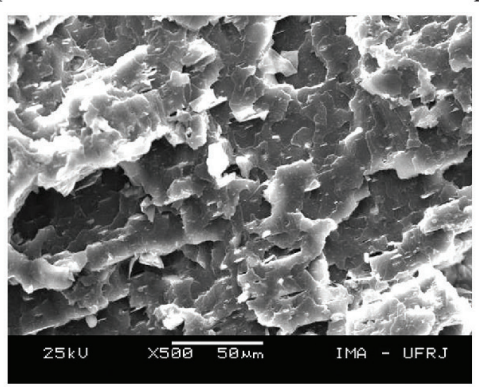

Sample E

Figure 8. Scanning Electron Microscope (SEM) Images of PLA samples fracture surfaces.

Generally, the $\mathrm{T}_{\mathrm{cc}}$ is important in industrial application when the processed articles are annealed for special purposes in order to increase their crystallinity and enhance their dimensional stability. Thus, a lower $\mathrm{T}_{c c}$ means that a lower energy is needed to achieve the crystallinity degree desired. As listed in Table 7, a $\mathrm{T}_{\mathrm{cc}}$ value was obtained with the addition of 3 wt. $\%$ of talc. In the others compositions, no crystallization peak on cooling scan was observed. Besides this, it also can be observed that in the range of 1 to $5 \mathrm{wt} . \%$ of talc addition, an increasing in the crystallinity degree was observed, indicating that a crystallization process after extrusion was achieved. However, no $\mathrm{T}_{\mathrm{cc}}$ peak was observed on the cooling scan in composites with 1 and $5 \mathrm{wt} . \%$ of talc. This behavior is not desirable when it's expected to produce articles with more dimensional stability from injection process, for example. The incorporation of $5 \mathrm{wt} \%$ seems only to have affected the orientation of the molecular chains in subsequent processing operations.

The Table 7 also shows that as talc was added a slight increasing on the melt temperature was observed. It is well known that the melting temperature is highly dependent on the crystal perfection. The increase on the Tm and crystallinity of PLA indicates that the nucleating agents enhanced the crystallization rate and improved the perfection of the crystals. Similar results were also presented by Kang et al. ${ }^{[1]}$.

Figure $7 \mathrm{a}$ shows the appearance of double melting peaks in PLA and PLA composites. The literature ${ }^{[18-21]}$ reveals that double melting behavior is a common phenomenon in semicrystalline polymers, such as PET, PA, PLA and its copolymers. Guim et al. ${ }^{[9]}$ informed that possibilities of double or multiple melting behaviors include the presence of different crystal forms, the presence of different morphologies (lamellar thickness 
and perfection) and recrystallization and remelting processes during the subsequent heating.

As previously mentioned, the Tg PLA $\left(55^{\circ} \mathrm{C}\right)$ was not greatly affected by the addition of the nucleating agent in the composition analyzed. It was also observed that a slight decrease in the Tg value was observed when 5 wt. $\%$ of talc was added. Similar results were obtained by Kang et al. ${ }^{[1]}$; however, Yu et al. ${ }^{[22]}$ observed a different behavior: the addition of talc in PLA resulted in an increase in glass transition temperature $(\mathrm{Tg})$, that was attributed to the strong interfacial interaction between talc and PLA, which reduced the free volume and restricted the motion of PLA chains, thereby raising the PLA Tg.

\section{Morphology properties}

The fracture surfaces were studied by SEM. According to Jiang et al. ${ }^{[23]}$, in the fracture processes of thermoplastic polymer materials, yield crazing or shear yielding occurs. As seem in Figure 8, the fracture surface of PLA appears more brittle since less plastic deformation can be detected on the fracture surface of the pure polymer. When talc is added to the PLA matrix, the fracture surface of PLA/talc showed characteristics of plastic deformation caused by more crazes, that appeared as talc content is increased. Even in the composition with more talc content (Sample E), no particle agglomeration appeared, indicating that a good dispersion of the filler on the melt was achieved.

\section{Conclusions}

The influence of talc addition as nucleation agent on the rheological, morphological and thermal properties was investigated in this study. The rheological measurements showed a Newtonian behavior of the PLA and PLA composites up to $10 \mathrm{rad} . \mathrm{s}^{-1}$, and then all the materials became pseudoplastic melts. The addition of $1 \mathrm{wt} \%$ of talc resulted in a decrease of the viscosity values due to the lubricant effect of the mineral filler on the PLA chains. As the talc content was increased up to $7 \mathrm{wt} . \%$, the viscosity values also increased, indicating a reinforcing effect of the filler on the PLA matrix. The thermal properties showed that no cold crystallization temperature, $\mathrm{T}_{c c}$, was observed in neat PLA and, among the compositions analyzed, the material with 3 wt.\% of talc showed better ability to induce the nucleation of PLA. This behavior is interesting since it indicates that a lower injection cycle can be achieved. The morphological analysis showed a brittle fracture surface of the neat PLA. As talc is added to the PLA matrix a shear yielding pattern characteristic of plastic deformation becomes evident. Besides this, it was observed a good dispersion of the filler during the melt processing.

\section{Acknowledgements}

The authors are grateful to the financial support of CAPES and CETEM to the characterization of the filler. We are also grateful to MAGNESITA COMPANY to supply the mineral filler, talc.

\section{References}

1. Kang, K. S.; Lee, S. I.; Lee, T. J.; Narayan, R. \& Shin, B. Y. - Korean J. Chem. Eng., 25, p.599 (2008). http://dx.doi. org/10.1007/s11814-008-0101-7
2. Hamad, K.; Kassem, M. \& Deri, F. - Polym. Bull., 65, p.509 (2010). http://dx.doi.org/10.1007/s00289-010-0354-2

3. Xu, H.; Teng, C. \& Yu, M. - Polymer, 47, p.3922 (2006). http://dx.doi.org/10.1016/j.polymer.2006.03.090

4. Feng, L. D.; Sun, B.; Bian, X. C.; Chen, Z. M. \& Chen, X. S. - Polym. Test., 29, p.771 (2010). http://dx.doi. org/10.1016/j.polymertesting.2010.06.005

5. Chen, B. K.; Shen, C. H.; Chen, S. C. \& Chen, A. F. - Polymer, 51, p.4667 (2010). http://dx.doi.org/10.1016/j. polymer.2010.08.028

6. Xiao, H.; Liu, F.; Jiang, T. \& Yeh, J. T. - J. Appl. Polym. Sci., 117, p.2980 (2010).

7. Pantani, R.; Santis, F.; Sorrentino, A.; Maio, F. \& Titomanlio, G. - Polym. Degrad. Stab., 95, p.1148 (2010). http://dx.doi.org/10.1016/j.polymdegradstab.2010.04.018

8. Li, H. \& Huneault, M. A. - Polymer, 48, p.6855 (2007). http://dx.doi.org/10.1016/j.polymer.2007.09.020

9. Guim, Z.; Lu, C. \& Cheng, S. - Polym. Test., 32, p.15 (2013).

10. Leong, Y. W.; Bakar, M. B.; Ishak, Z. A. M.; Ariffin, A.; Pukanszky, B. - J. Appl. Polym. Sci., 91, p.3315 (2004). http://dx.doi.org/10.1002/app.13542

11. Barnes, H. A. - Rheol. Rev., 36, p.1 (2003).

12. Silva, A. L. N.; Rocha, M. C. G.; Coutinho, F. M. B.; Bretas, R. \& Scuracchio, C. - Polym. Test., 19, p.363 (2000).

13. Dealy, J. M. \& Wissbrun, K. F. - "Melt Rheology and Its Role in Plastics Processing - Theory and Applications", Kluwer Academic Publishers, Dordrecht, Boston, London (1999).

14. Silva, A. L. N.; Rocha, M. C. G.; Coutinho, F. M. B.; Bretas, R. \& Scuracchio, C. - J. Appl. Polym. Sci, 75, p.692 (2000). http://dx.doi.org/10.1002/(SICI)10974628(20000131)75:5<692::AID-APP12>3.0.CO;2-Y

15. Wagener, R. \& Reisinger, T. J. G. - Polymer, 44, p.7513 (2003). http://dx.doi.org/10.1016/j.polymer.2003.01.001

16. Souza, D. H. S.; Andrade, C. T. \& Dias, M. L. - Mater. Sci. Eng. C., 33, p.1795 (2013). PMid:23827638. http://dx.doi. org/10.1016/j.msec.2012.12.091

17. Lim, L. T.; Auras, R. \& Rubino, M. - Prog. Polym. Sci., 33, p.820 (2008). http://dx.doi.org/10.1016/j. progpolymsci.2008.05.004

18. Shan, G. F.; Yang, W.; Tang, X. G.; Yang, M. B.; Xie, B. H.; Fu, Q. \& Mai, Y. W. - Polym. Test., 29, p.273 (2010). http:// dx.doi.org/10.1016/j.polymertesting.2009.11.011

19. Sarasua, J. R.; Prud'homme, R. E.; Wisniewski, M.; Borgne, A. \& Spassky, N. - Macromolecules, 31, p.3895 (1998). http://dx.doi.org/10.1021/ma971545p

20. Wang, Y. \& Mano, J. F. - Polym. Test., 28, p.452 (2009). http://dx.doi.org/10.1016/j.polymertesting.2009.03.006

21. Yasuniwa, M.; Sakamo, K.; Ono, Y. \& Kawahara, W. - Polymer, 49, p.1943 (2008). http://dx.doi. org/10.1016/j.polymer.2008.02.034

22. Yu, F.; Liu, T.; Zhao, X.; Yu, X.; Lu, A.; Wang, J. - J. Appl. Polym. Sci, 125, p.99 (2012). http://dx.doi.org/10.1002/ app. 36260

23. Jiang, L.; Zhang, J. \& Wolcott, M. P. - Polymer, 48, p.7632 (2007). http://dx.doi.org/10.1016/j.polymer.2007.11.001

Received: 08/25/13

Revised: 02/18/14

Accepted: 03/18/14 